\title{
Inhibitory effects of berberine on proinflammatory M1 macrophage polarization through interfering with the interaction between TLR4 and MyD88
}

Jing Gong ${ }^{1}$, Jingbin Li ${ }^{1}$, Hui Dong ${ }^{1,2}$, Guang Chen ${ }^{1}$, Xin Qin², Meilin Hư ${ }^{1}$, Fen Yuan ${ }^{1}$, Ke Fang ${ }^{1}$, Dingkun Wang ${ }^{1}$, Shujun Jiang ${ }^{1}$, Yan Zhao ${ }^{1}$, Wenya Huang ${ }^{1}$, Zhaoyi Huang ${ }^{1 *}$ and Fuer Lu ${ }^{1 *}$

\begin{abstract}
Backgrounds: Inflammation is recognized as the key pathological mechanism of type 2 diabetes. The hypoglyceamic effects of berberine (BBR) are related to the inhibition of the inflammatory response, but the mechanism is not completely clear.
\end{abstract}

Methods: The inflammatory polarization of Raw264.7 cells and primary peritoneal macrophages were induced by LPS, and then effects and underlying mechanisms of BBR were explored. An inflammatory model was established by LPS treatment at different concentrations for different treatment time. An ELISA assay was used to detect the secretions of TNF- $a$. RT-PCR was applied to detect M1 inflammatory factors. The F $4 / 80^{+}$ratio and CD11 $\mathrm{c}^{+}$ratio of primary peritoneal macrophages were determined by flow cytometry. The expressions of p-AMPK and TLR4 were detected by Western blot. The cytoplasmic and nuclear distributions of NFkB p65 were observed by confocal microscopy. The binding of TLR4 to MyD88 was tested by CoIP, and the affinity of BBR for TLR4 was assessed by molecular docking.

Results: Upon exposure to LPS, the secretion of TNF-a and transcription of inflammatory factors in macrophages increased, cell morphology changed and protrusions appeared gradually, the proportion of $\mathrm{F} 4 / 80^{+} \mathrm{CD} 11 \mathrm{C}^{+} \mathrm{M} 1$ macrophages increased, and the nuclear distribution of NFKB p65 increased. BBR pretreatment partially inhibited the changes mentioned above. However, the expression of TLR4 and p-AMPK did not change significantly after LPS intervention for $3 \mathrm{~h}$. Meanwhile, CoIP showed that the interaction between TLR4 and MyD88 increased, and BBR inhibited the binding. Molecular docking suggested that BBR might interact with TLR4.

Conclusions: Inflammatory changes were induced in macrophages after LPS stimulation for $3 \mathrm{~h}$, and BBR pretreatment inhibited inflammatory polarization. BBR might interact with TLR4 and disturb TLR4/MyD88/NFKB signalling pathway, and it might be the mechanism by which BBR attenuated inflammation in the early phase.

Keywords: Berberine, Macrophage, Inflammatory polarization, Lipopolysaccharide

\footnotetext{
*Correspondence: huangzhaoyi@163.com; felu@tjh.tjmu.edu.cn

Chemical compounds studied in this article: Berberine (PubMed CID: 12456)

'Department of Integrated Traditional Chinese and Western Medicine, Tongji

Hospital, Tongji Medical College, Huazhong University of Science and

Technology, Wuhan 430030, Hubei, China

Full list of author information is available at the end of the article
}

(c) The Author(s). 2019 Open Access This article is distributed under the terms of the Creative Commons Attribution 4.0 International License (http://creativecommons.org/licenses/by/4.0/), which permits unrestricted use, distribution, and reproduction in any medium, provided you give appropriate credit to the original author(s) and the source, provide a link to the Creative Commons license, and indicate if changes were made. The Creative Commons Public Domain Dedication waiver (http://creativecommons.org/publicdomain/zero/1.0/) applies to the data made available in this article, unless otherwise stated. 


\section{Background}

Inflammation is the key pathological mechanism of type 2 diabetes (T2DM) [1]. The infiltration of immune cells and the activation of inflammatory signals in adipose tissue have been found to be important characteristics of T2DM [2]. The inflammatory cells in the adipose tissue of obese mice produced cytokines, including IL-6, TNF- $\alpha$, IL- $1 \beta$ and macrophage migration inhibitory factor [3]. More than 100 years ago, researchers observed that salicylate, the main metabolite of the anti-inflammatory drug aspirin, was beneficial for the blood glucose levels of patients with T2DM [4]. In 1993, Hotamisligil and colleagues found that TNF- $\alpha$ secreted by inflammatory cells in the adipose tissue of obese mice inhibited insulin signal transduction [5]. Subsequent clinical trials showed that inflammatory markers in the circulation indicated the risk of T2DM, plasma TNF- $\alpha$ and IL- 6 concentrations in patients with T2DM increased, and the antiinflammatory medicine salicylate could improve the metabolic imbalance [6-8]. In obese mice, the neutralization of TNF- $\alpha$ or IL- $1 \beta$ could reduce inflammation and improve insulin signalling [9].

Macrophages are the main sources of the inflammatory mediators TNF- $\alpha$ and IL- 6 in the pathogenesis of T2DM $[10,11]$. In obese and T2DM patients and animal models, monocytes in circulation are recruited to the adipose tissue, liver, pancreas, skeletal muscle and brain [12], and the accumulation of macrophages lead to local inflammation, islet $\beta$ cell dysfunction and insulin resistance [13-15]. Under different metabolic conditions, macrophage populations differ in number, and phenotypic and functional changes also appear in metabolic tissues. According to surface markers and cytokine secretion, macrophages can be roughly divided into M1 and M2 macrophages [16-18]. For example, in the adipose tissue of healthy people, the macrophages are mainly the M2 type, while in obese and T2DM patients, M1 macrophges increase. M1 macrophages mainly secrete inflammatory cytokines, such as TNF- $\alpha$, IL-1 $\beta$ and IL-6, which induce insulin resistance; M2 macrophages express anti-inflammatory factors, increase the differentiation of islet $\beta$ cells and improve insulin signalling [19]. Inhibiting M1 polarization has become a promising strategy for the prevention and treatment of T2DM.

Berberine (BBR) was found to reduce the proportion of macrophages in the intestinal immune system [20] and inhibit the expression of inflammatory cytokines such as TNF- $\alpha$, IL-1 $\beta$ and MIP1 in T2DM rats, and the inhibition of inflammation by BBR was related to the TLR4/MyD88/NFKB signalling pathway [21]. This study further explored the mechanism by which BBR inhibited the M1 macrophage polarization.

\section{Materials and methods}

\section{Cell source and culture medium}

Raw264.7 cells were gifts from the Union Hospital of Tongji Medical College, Huazhong University of Science and Technology. Kunming female mice weighing between 30 and 40 $\mathrm{g}$ were purchased from Hubei Disease Control Center and were used for the extraction of primary peritoneal macrophages. The animal ethics committee of Huazhong University of Science and Technology approved the study.

\section{Culture medium}

Complete medium containing $10 \mathrm{ml}$ of Gibco fetal bovine serum (FBS), $1 \mathrm{ml}$ penicillin (100 units $/ \mathrm{ml}$ ) and streptomycin $(100 \mathrm{mg} / \mathrm{ml})$ and $89 \mathrm{ml}$ of high-glucose DMEM was prepared. This complete medium was employed for cell culture and passage.

Synchronous medium, containing $1 \mathrm{ml}$ of Gibco FBS, $1 \mathrm{ml}$ of penicillin and streptomycin and $98 \mathrm{ml}$ highglucose DMEM, was used for reagent configuration, cell synchronization and intervention in Raw264.7 cells.

\section{Raw264.7 cell culture conditions and treatment}

Cells were incubated at $37^{\circ} \mathrm{C}$ with $5 \% \mathrm{CO} 2 / 95 \%$ air in complete medium. When the cells reached $50-60 \%$ confluence rate, they were subcultured. Before drug intervention, the cells were pre-incubated in synchronous medium for $12 \mathrm{~h}$; then exposed to corresponding agents for the scheduled time.

\section{Extraction method of primary peritoneal macrophages}

Female Kunming mice were sacrificed by cervical spine dislocation, soaked in $75 \%$ alcohol for $10 \mathrm{~min}$ and fixed. Then, the outer peritoneum was gentle sectioned and sufficiently separated from the inner layer. After the inner layer of the peritoneum was exposed, $12 \mathrm{ml}$ of physiological saline was slowly injected into the abdominal cavity under the centre of the abdomen. After gentle shaking for $5 \mathrm{~min}$, the peritoneal rinse liquid was slowly extracted from both sides of the peritoneum [22]. The collected cells were placed on ice. The extractions were repeated three times for each mouse. After centrifugation, cells were inoculated into 6-well or 12-well plates, and the medium was changed $30 \mathrm{~min}$ later. Following incubation for $6 \mathrm{~h}$, the agent intervention was initiated.

\section{Preparation of LPS}

A total of $10 \mathrm{mg}$ of LPS was dissolved in $10 \mathrm{ml}$ of an aseptic PBS solution and gently shaken until completely dissolution. The LPS solution was vibrated for $30 \mathrm{~min}$ and was stored at $-20^{\circ} \mathrm{C}$. LPS was diluted to different concentrations, namely, $10^{-4}, 10^{-5}, 10^{-6}, 10^{-7}$ and $10^{-8} \mathrm{mg} / \mathrm{ml}$. Each dilution was vortexed for $10 \mathrm{~min}$ before being used. 
Preparation of BBR, metformin, AICAR and compound C BBR was dissolved in the methanol-ethanol solution at the concentration of $3.345 \mathrm{mg} / \mathrm{mL}$. After sterilization by filtration, and the stock solution of $0.01 \mathrm{M}$ BBR was sealed, protected from light and stored at $4{ }^{\circ} \mathrm{C}$. The $\mathrm{BBR}$ stock solution was diluted with synchronized culture medium to obtain various working solutions. A total of $33.12 \mathrm{mg}$ metformin was dissolved in $2 \mathrm{ml}$ of synchronous medium, filtered for sterility, and stored at $-20^{\circ} \mathrm{C}$. Synchronous medium was used to dilute the stock solution of metformin to the appropriate concentration for use in the experiment. 5-Aminoimidazole-4-carboxamide1- $\beta$-D-ribofuranoside (AICAR) and compound C were prepared according to the manuscripturer's instructions. Pretreatment with BBR, metformin and other agents were applied before LPS intervention.

\section{MTT assay}

Raw264.7 cells in the logarithmic phase were collected, and the cell suspension concentration was adjusted. One hundred microliter medium containing 6000 cells was added to each well of a 96-well plate. After incubation for $12 \mathrm{~h}, \mathrm{BBR}$, metformin, AICAR or Compound $\mathrm{C}$ were added according to the corresponding concentration gradient. In addition, the normal control group and blank well were set up. The supernatant was discarded $24 \mathrm{~h}$ later, and the wells were washed once with PBS. MTT solution dissolved in high-glucose DMEM was administered for $4 \mathrm{~h}$. The supernatant of each well was carefully removed, and $100 \mu \mathrm{l}$ of DMSO was then added to the wells for $30 \mathrm{~min}$. A spectrophotometer (Bio-Tek, USA, Model: Synergy2) was used to measure the absorbance at $490 \mathrm{~nm}$, and the cell survival rate was calculated.

\section{ELISA assay}

A TNF- $\alpha$ ELISA kit (Boster, China) was used to detect the TNF- $\alpha$ concentrations in the supernatant. In brief, $100 \mu \mathrm{l}$ of supernatant was added to each well according to the instructions, and the corresponding OD values were measured at $450 \mathrm{~nm}$ using a spectrophotometer (Synergy2, USA). The TNF- $\alpha$ levels were adjusted according to the cell number in each well.

\section{RT-PCR}

RNA was extracted from the cells by Trizol reagent, the RNA concentration was determined, and reverse transcriptase kits were used to obtain cDNA. RNA concentration was examined by Nanodrop spectrophotometer (Thermo Scientific, America), and the samples with A260/A280 in the range of 1.8 to 2.0 were used for further study. Subsquently, a SYBR premix EX TaqTM kit (Takara, China) was used for amplification on a StepOne PCR detetor (Stepone, USA). The mRNA expression levels were calculated using $2^{-\Delta} \Delta \mathrm{CT}$ method. The primer sequences are shown in Table 1.

\section{Western blot analysis}

Proteins were extracted from the cells and separated by gel electrophoresis, transferred onto PVDF membranes, and incubated with antibodies against TLR4 (Abcam, UK), p-AMPK (CST, USA), and AMPK (CST, USA). Then, these membranes were co-incubated with corresponding secondary antibodies. The protein levels were determined by an Odyssey imaging system (LI-COR Biosciences, Lincoln, NE).

\section{Immunofluorescence assay}

Cells were seeded on glass coverslips in a 12-well plate at a density of $5 \times 10^{5}$ cells per well, and paraformaldehyde fixation was performed after treatment. Afterwards, these cells were immunostained overnight with primary antibodies against NFkB p65 (CST, USA). Then fluorescent secondary antibodies were co-incubated at room temperature for $30 \mathrm{~min}$. After being rinsed, the cells were stained with DAPI (Sigma, USA) for $3 \mathrm{~min}$ and sealed. Finally, the cells were observed and imaged under a laser confocal microscope (Japan, Nikon, C2+/C2si+).

Table 1 Primers in RT-PCR

\begin{tabular}{|c|c|c|}
\hline Gene & Forward $\left(5^{\prime} \rightarrow 3^{\prime}\right)$ & Reverse $\left(5^{\prime} \rightarrow 3^{\prime}\right)$ \\
\hline LBP & CCCAGACGCTGGATGTGATG & TGATCTGAGATGGCAAAGTAGACC \\
\hline CD14 & CTTATGCTCGGCTTGTTGCTGT & TAGCAGCGGACACTTTCCTCGT \\
\hline$I L-1 \beta$ & GTCGGGACATAGTTGACTTCAC & GACTTGGCAGAGGACTTCAC \\
\hline TNF-a & CCAGGTTCTCTTCAAGGGACAA & GGTATGAAATGGCAAATCGGCT \\
\hline IL-10 & GCTGGACAACATACTGCTGAC & AATGCTCCTTGATTTCTGGG \\
\hline $\mid \mathrm{L}-4$ & CTGTCACCCTGTTCTGCTITCTC & TाTCTGTGACCTGGTTCAAAGTGT \\
\hline TGF- $\beta$ & AAGGACCTGGGTTGGAAGT & CGGGTTGTGTTGGTTGTAGA \\
\hline IL-6 & AATCTGCTCTGGTCTTCTGGA & CAGTATTGCTCTGAATGACTCTGG \\
\hline MIP1 & GACTTTAAGTGGCACGAGCG & GCTTGCTGTAGTTGCGGTTCT \\
\hline TNFR & ACCCTCACACTCACAAACCA & ATAGCAAATCGGCTGACGGT \\
\hline$\beta$-actin & AGCCATGTACGTAGCCATCC & CTCTCAGCTGTGGTGGTGAA \\
\hline
\end{tabular}



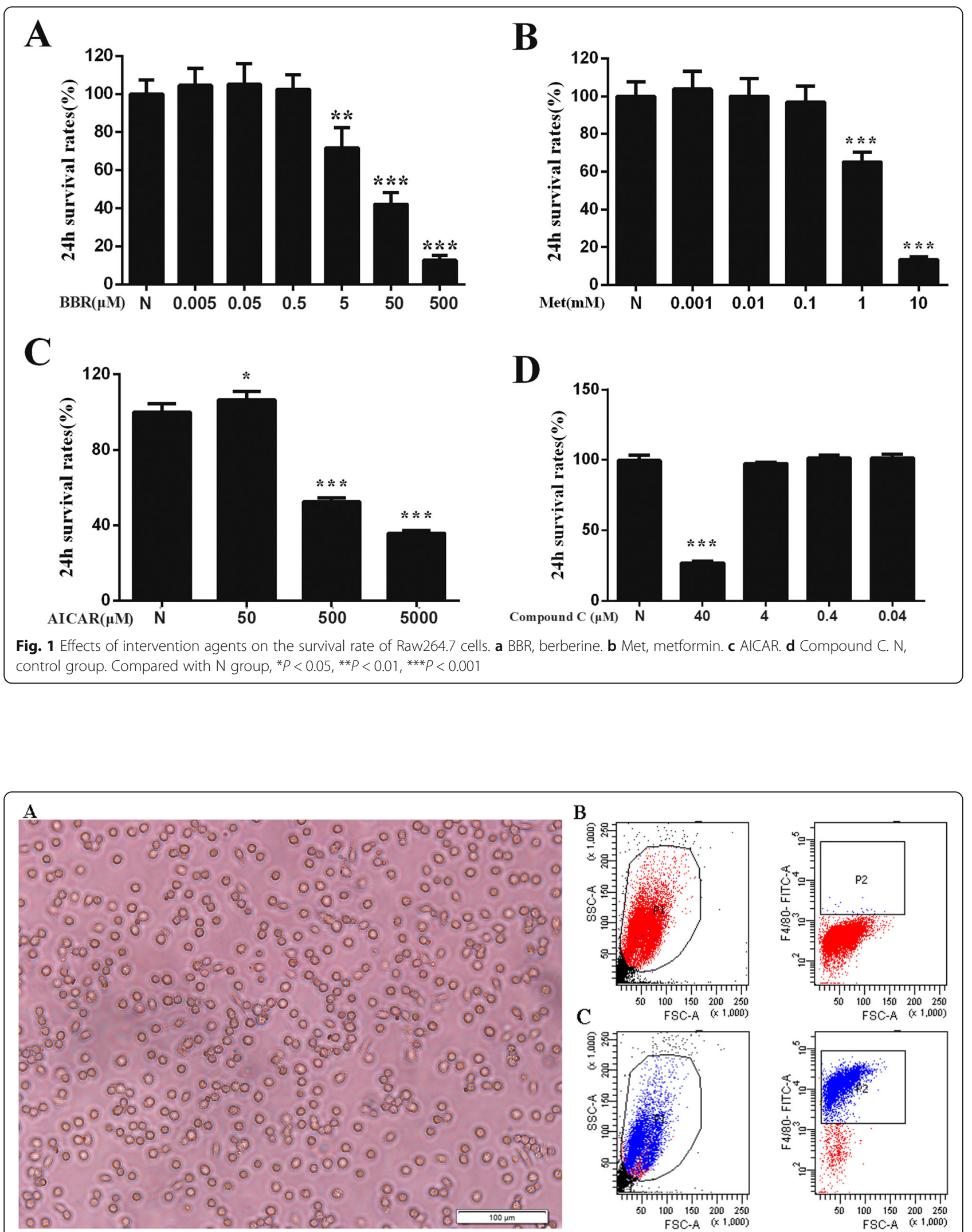

Fig. 2 Peritoneal macrophage morphology (a) and proportion identification (b-c). b Negative controls without antibodies. c Macrophages labelled by F $4 / 80$ 


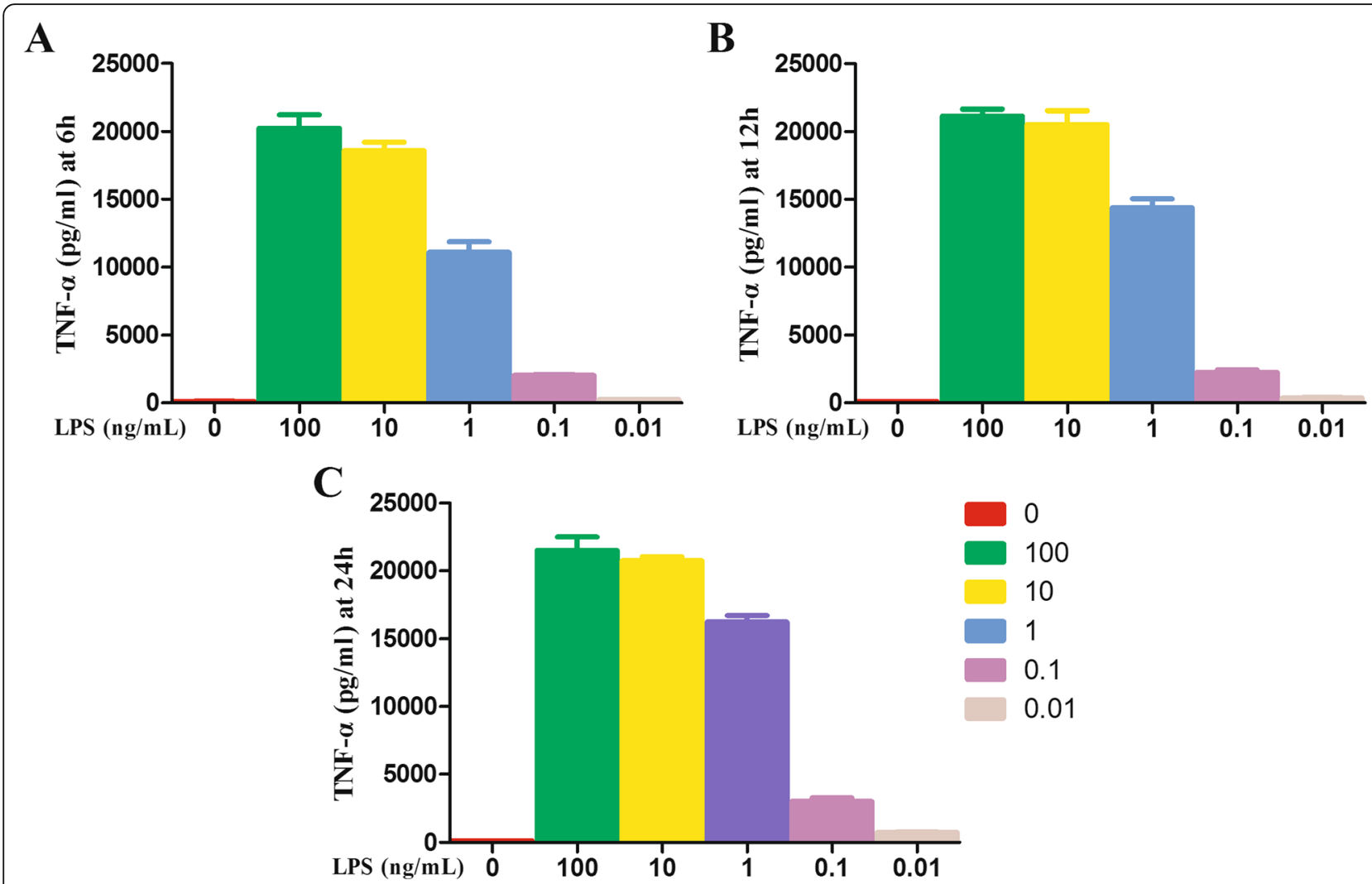

Fig. 3 TNF-a levels in the supernatant after Raw264.7 cells were exposed to LPS at different concentrations for $6 \mathrm{~h}$ (a), $12 \mathrm{~h}$ (b) or $24 \mathrm{~h}$ (c)

\section{ColP}

Approximately $10^{7}$ cells were seeded in each $6-\mathrm{cm}$ dish and exposed to LPS and/or BBR for $3 \mathrm{~h}$. Then, protein was extracted as described above and immunoprecipitated with anti-MyD88 for $1 \mathrm{~h}$ at $4{ }^{\circ} \mathrm{C}$. The samples were incubated with protein A/G-Sepharose overnight at $4{ }^{\circ} \mathrm{C}$ under constant rotation and then washed with CoIP wash buffer 4 times [23]. Western blotting was used as described above to detect the levels of TLR4 and MyD88 in the immunoprecipitated samples.

\section{Determination of the ratio of peritoneal macrophages by flow cytometry}

Cells were collected after treatment and then incubated with F4/80 (eBioscience, USA) or CD11c (BD Bioscience, USA) antibody in the dark for $30 \mathrm{~min}$. The reaction was terminated with PBS, and the cells were fixed using $1 \%$ paraformaldehyde after rinsing. The M1 ratio was tested by flow cytometry (BD FACSCalibur, USA).

\section{Molecular docking}

The PubChem and UniPROtkb databases were searched to obtain the structure of BBR and the PDB ID of TLR4. The protein structure of TLR4 was obtained from the RCSB PDB database. Chimera (http://www.cgl.ucsf.edu/chimera/) and Avogardora (https://avogadro.cc/) software were used to optimize the structure of BBR. After optimizing the TLR4 structure by Autodock software (http://www.scripps. edu/mb/olson/doc/autodock), the 3D active centres in the A chain, B chain, C chain and D chain of TLR4 were docked with BBR separately. During the simulation, the ligands were allowed to rotate freely; based on the probe atoms of the corresponding ligand atoms, the AutoGrid module was used to detect the active region of the target protein and generate a potential energy map. Through docking analysis, whether BBR can interact with the active centre of TLR4 was assessed.

\section{Statistical analysis}

SPSS 20.0 software was used to analyse the data. The K$\mathrm{S}$ normality test was performed to evaluate the homogeneity of variance, and ANOVA was used to determine significance. Significance between different groups was assessed using the Bonferroni test. Differences were considered significant when the $P$ value $<0.05$.

\section{Results}

Effects of intervention agents on the survival rate of Raw264.7 cells

$\mathrm{BBR}$, metformin, AICAR, and compound $\mathrm{C}$ were prepared in synchronous culture medium. Different concentrations of these agents were added to Raw264.7 cells for $24 \mathrm{~h}$, and the 

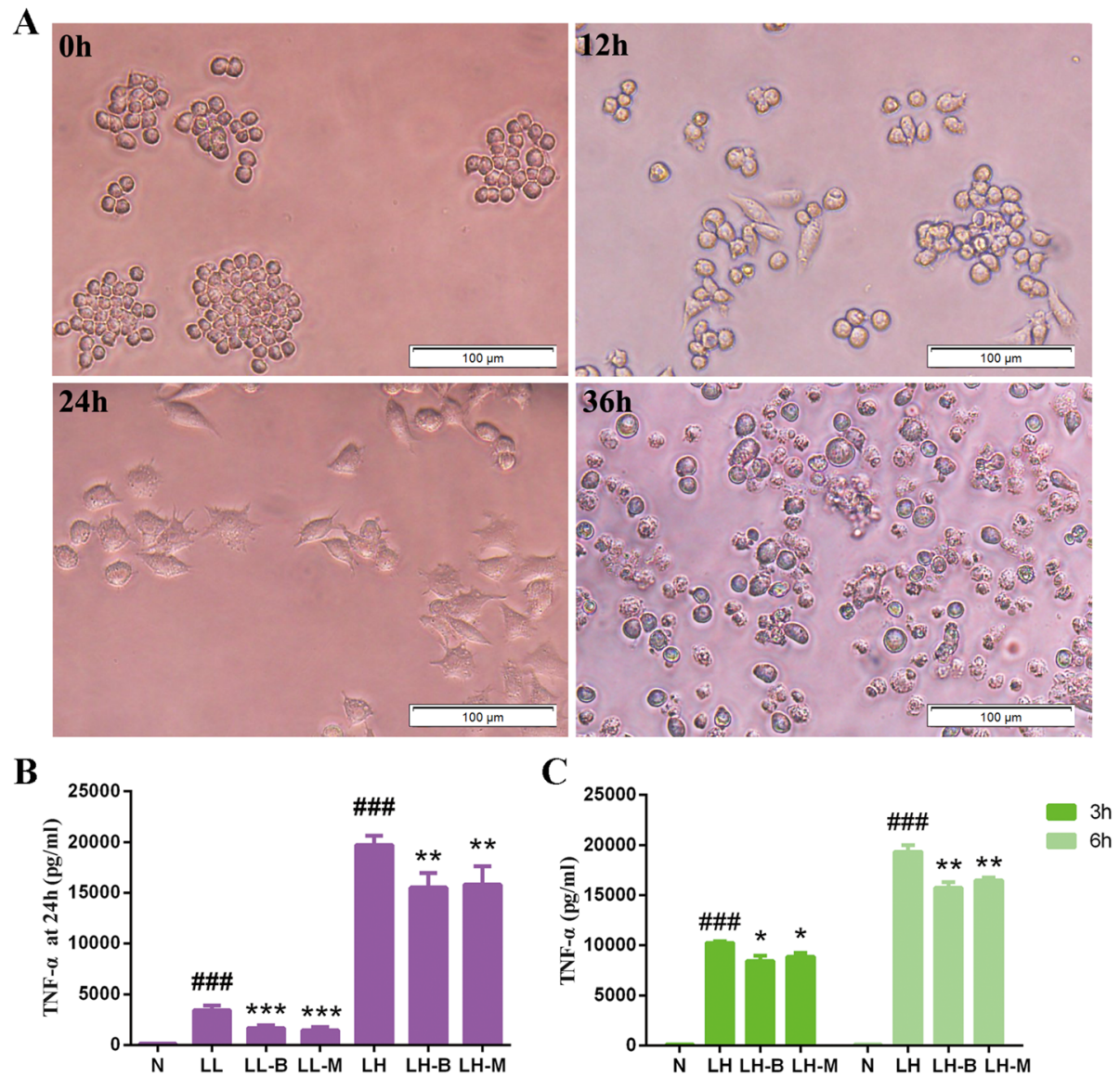

Fig. 4 Morphological changes after high-dose LPS intervention (a) and the effects of BBR on LPS-induced TNF-a secretion (b-c) in Raw264.7 cells at different times. N, control group; LL, $0.1 \mu M$ LPS group; LL-B, $0.1 \mu M$ LPS + BBR group; LL-M, $0.1 \mu M$ LPS + Metformin group; LH, 0.1 mM LPS group; LH-B, 0.1 mM LPS +

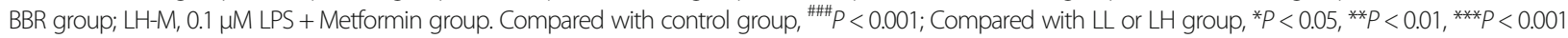

cell survival rates were compared. Combined with previous research results, the maximum concentration that did not induce significant cytotoxicity was set as the concentration for subsequent experiments. As shown in Fig. 1, the intervention concentration of BBR was $0.5 \mu \mathrm{M}$, the concentration of metformin was $0.1 \mathrm{mM}$, the concentration of AICAR was $50 \mu \mathrm{M}$, and the concentration of Compound $\mathrm{C}$ was $4 \mu \mathrm{M}$.

\section{Identification of primary peritoneal macrophages}

Peritoneal macrophage morphology and ratios were evaluated. Under light microscopy, the peritoneal macrophages extracted from the mice were round and scattered with a few fusiform fibroblasts (Fig. 2a). Macrophage ratio was determined by FITC-labelled F4/80. As shown in Fig. 2b$\mathrm{c}$, the macrophage ratio in the peritoneal lavage fluid was about $90 \%$.

\section{Effects of LPS on morphology and TNF-a secretion in Raw264.7 macrophages}

When Raw264.7 cells were exposed to $100,10,1,0.1$ or $0.01 \mathrm{ng} / \mathrm{ml}$ LPS for $6 \mathrm{~h}, 12 \mathrm{~h}$ or $24 \mathrm{~h}$, the inflammatory TNF- $\alpha$ in the cell supernatant were significantly increased (Fig. 3). Concentration of $100 \mathrm{ng} / \mathrm{ml}$ and $0.1 \mathrm{ng} / \mathrm{ml}$ were then chosen as the high and low treatment doses for the subsequent experiment (LH, high dose of LPS; LL, low dose of LPS).

In addition to the changes in TNF- $\alpha$ secretion, the Raw264.7 cells gradually became larger when exposed to high or low doses of LPS. With the prolongation of the intervention time, the cells especially those in the high dose group, extended several protrusions. After exposure to a high dose of LPS for $36 \mathrm{~h}$, a large number of fragmentations were observed, and death occurred in the cells (Fig. 4a).

\section{Effects of BBR on inflammation induced by LPS in macrophages}

BBR inhibited the secretion of TNF- $\alpha$ in Raw264.7 cells after intervention with LPS for $3 \mathrm{~h}$ and $24 \mathrm{~h}$ (Fig. $4 \mathrm{~b}-\mathrm{c}$ ), and BBR did not significantly improve the morphological changes in Raw264.7 cells induced by high dose LPS.

After treatment with $0.1 \mu \mathrm{g} / \mathrm{ml}$ LPS for $6 \mathrm{~h}$, some peritoneal macrophages extended their protrusions, and the secretion of TNF- $\alpha$ in the supernatant increased. 


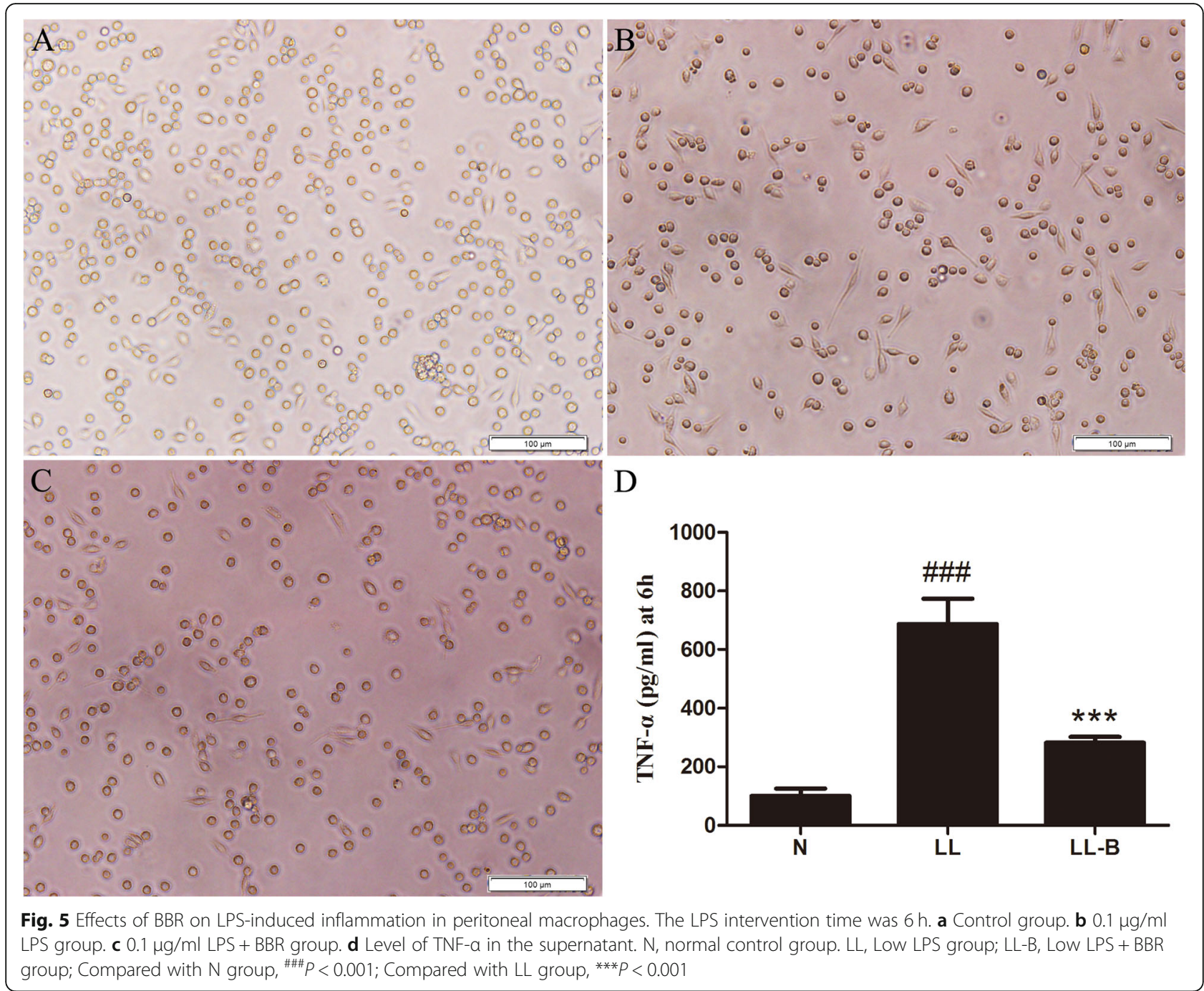

However, BBR pretreatment inhibited the morphological changes induced by LPS and the secretion of TNF- $\alpha$ in the supernatant (Fig. 5).

\section{Effects of BBR on M1 polarization induced by LPS}

After LPS treatment, the transcription of IL- 6 , TNF- $\alpha$ and MIP1 increased, and iNOS2 expression was upregulated. BBR pretreatment inhibited the upregulation of LPS-induced inflammatory markers in Raw264.7 macrophages (Fig. 6). After LPS intervention, the proportion of $\mathrm{CD}_{11 \mathrm{c}^{+}} \mathrm{M} 1$ polarized macrophages was upregulated, while $\mathrm{BBR}$ pretreatment inhibited the increase in F4/ $80^{+} \mathrm{CD} 11 \mathrm{c}^{+}$peritoneal cells, decreasing the numbers of inflammatory polarized macrophages (Fig. $7 \mathrm{a}-\mathrm{d}$ ).

\section{Effects of BBR on the expressions of regulatory proteins related to macrophage polarization}

The M1 polarization of macrophages was regulated by signalling molecules, such as the components of the
TLR4/MyD88/NFkB pathway, TNFR, AMPK $\alpha 1$ and other TLRs, among which the components of the TLR4 signalling pathway were the most important. Thus, the protein and mRNA expression levels of these inflammatory signal molecules were detected. As mentioned above, after LPS intervention for $3 \mathrm{~h}$ and $6 \mathrm{~h}$, TNF- $\alpha$ secretion was significantly increased, and meanwhile BBR inhibited the expression of inflammatory factors. Immunofluorescence also showed that the nuclear transloacation of $\mathrm{Nf} f_{K} B$ p65 was significantly increased, and BBR decreased the level of NFKB p65 in the nucleus after LPS intervention for $3 \mathrm{~h}$ (Fig. 7e-g).

BBR had significant anti-inflammatory effects upon intervention with LPS for $3 \mathrm{~h}$, and RT-PCR and Western blotting showed that BBR did not significantly improve the mRNA and protein levels of TLR4 at this time point (Figs. 8 and 9a). However, there were no significant differences in the secretions of TNF- $\alpha$ after pretreatment with AICAR or compound C or LPS stimulation for $3 \mathrm{~h}$ 

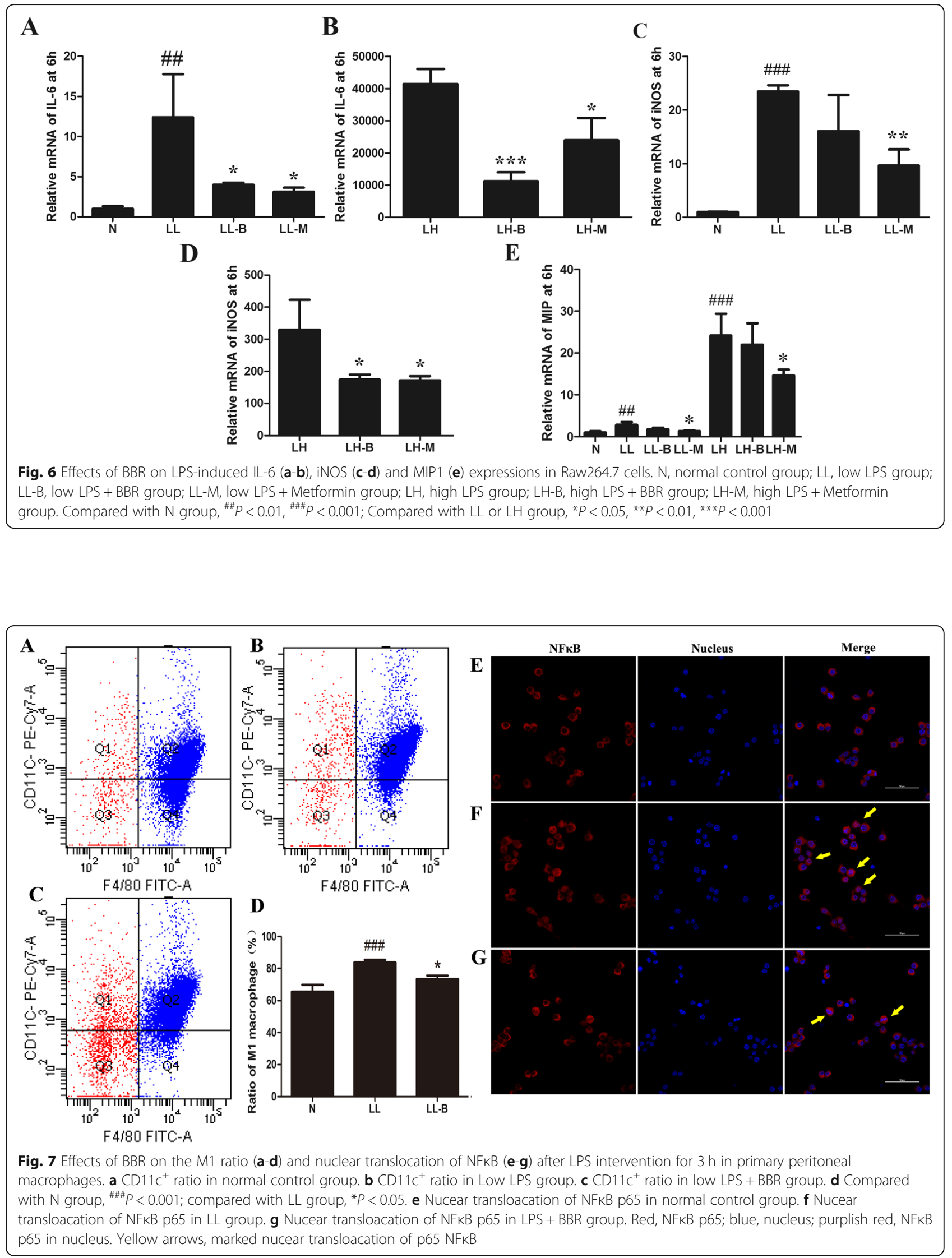
(results not shown). Meanwhile, agonists and inhibitors of AMPK $\alpha$ did not significantly improve the inflammatory response induced by LPS for $3 \mathrm{~h}$. The expression levels of TLR4, p-AMPK and TNFR might not reflect the mechanism by which BBR inhibited M1 macrophage polarization after LPS intervention for $3 \mathrm{~h}$.

\section{Effects of BBR on the interaction between TLR4 and MyD88}

The interaction between TLR4 and MyD88 was detected by CoIP. The results showed that the interaction between TLR4 and MyD88 increased after LPS intervention for $3 \mathrm{~h}$, and BBR inhibited the binding of TLR4 to MyD88 (Fig. 9b, Additional file 1: Figure S1). Based on structural biology, BBR interacted with the A chain, B chain and C chain of TLR4, and its affinity for the A chain binding site was the highest (Fig. 9c-e), the I conformation number was 100 , and the docking free energy was $-6.69 \mathrm{kcal} / \mathrm{mol}$.

\section{Discussion}

M1 macrophages secreted inflammatory cytokines, such as TNF- $\alpha$, IL-6, IL-1 $\beta$, MCP-1 and MIF-1, which affected insulin sensitivity [24], and inhibiting inflammation can improve insulin function. Similar to previous studies, this study found that BBR inhibited M1 polarization. Notably, the inflammatory mediators were significantly increased after LPS treatment for $3 \mathrm{~h}$; meanwhile, the anti-inflammatory effects of BBR were obvious. The production of these inflammatory factors was mainly promoted by the nuclear translocation of $\mathrm{NFKB}$ p65 [25], and the activation of NFKB in macrophages was regulated by many signalling pathways, such as pathways involving TLRs, AMPK $\alpha 1$ and TNFR [26-28]. Then we explored the mechanism by which BBR inhibited M1 polarization. However, the transcriptional changes in TNFR, TLR1, TLR2, TLR5 and TLR6 seemed not the answers. Consistent with the finding that agonists and inhibitors of AMPK $\alpha$ did not significantly improve the inflammatory response, the expression of p-AMPK did not change significantly after LPS intervention for $3 \mathrm{~h}$.

TLR4 plays the most important role in macrophage inflammation mediated by LPS [29]. The specific knockout of TLR4 in myeloid cells inhibited insulin resistance in high-fat-diet-fed mice [30]. TLR4 can anchor MyD88 and promote the nuclear translocation of $\mathrm{NFKB}$ to induce the expression of inflammatory factors [31]. In fact, some studies have found that the anti-inflammatory effect of BBR is related to TLR4 expression [32, 33]. In this study, macrophage inflammation and anti-inflammatory effects of BBR appeared after LPS intervention for $3 \mathrm{~h}$ and TLR4 protein levels did not increase at the same time. Therefore, the mechanism underlying the action of BBR was further analysed based on structural biology. The results of CoIP and molecular docking showed that the affinity of BBR for TLR4 was high, and the interaction between TLR4 and MyD88 was inhibited by BBR. Thus, the inhibition of inflammation by BBR in the early phase may be related to its interaction with TLR4, which may interfere with the binding of MyD88 to TLR4.

One intriguing finding of this study was that BBR can interact with TLR4 to interfere with inflammatory signalling

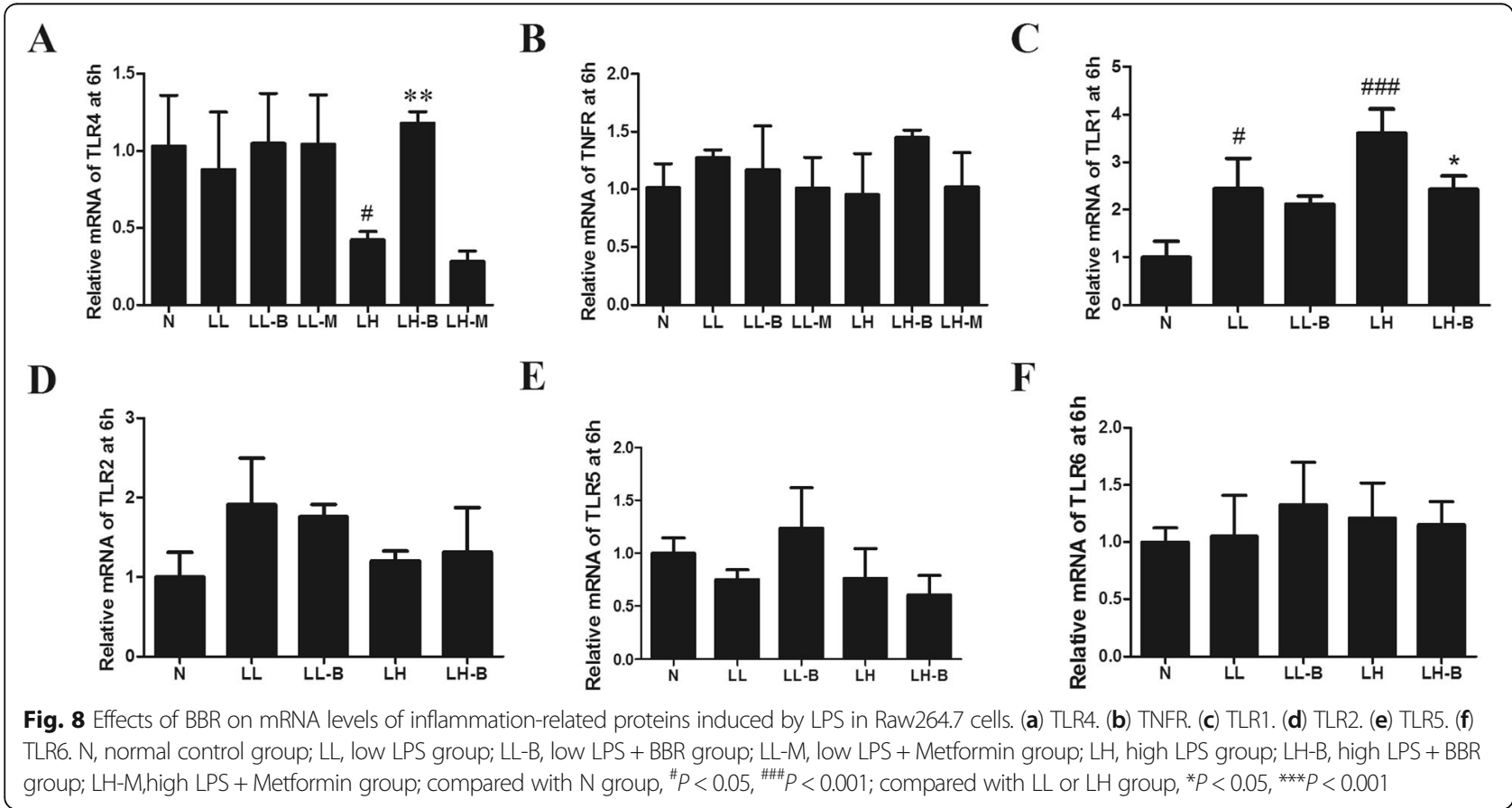




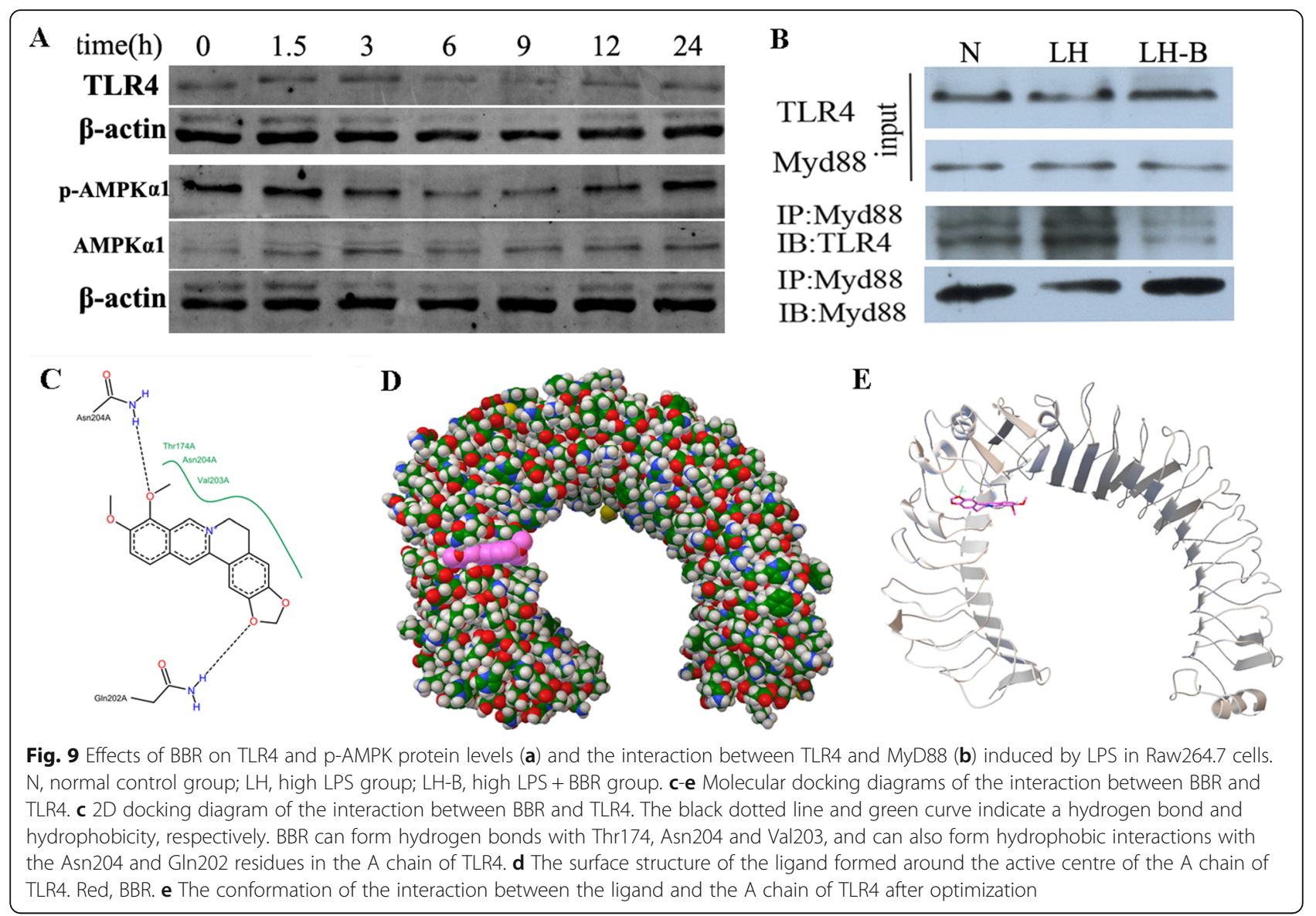

pathway. In fact, the TLR4 signalling pathway could also be regulated by many mechanisms. Inflammatory factors could induce the upregulation of TLR4 expression, while sTLR4, RP105, MyD88s, A20 and miRNA-21 were negative regulatory elements [34]. These negative regulatory factors could affect TLR4 through degradation, deubiquitination and competitive binding [35], and this may explain the decreasing trend of TLR4 after LPS treatment for $9 \mathrm{~h}$. In addition, TLR4 is a transmembrane protein that consists of three parts: the extracellular, intracellular and transmembrane regions [27]. The extracellular segments are involved in the recognition of LPS and the intracellular segments are involved in signal transduction. BBR seemed to interact with TLR4 at several sites, and the precise function site needs to be further confirmed.

In conclusion, this study showed that BBR could inhibit the pro-inflammatory M1 polarization of macrophages in the early phase, and that the effects were related to interference in the process of TLR4 and MyD88 binding and the nuclear translocation of $\mathrm{NF}_{\mathrm{K}} \mathrm{B}$ p65. Interference in the TLR4/MyD88/NFKB signalling pathway inhibits metabolic inflammation based on structural biology, which may be a new mechanism by which BBR prevents and treats T2DM.

\section{Conclusions}

Inflammatory changes were induced in macrophages after LPS stimulation for $3 \mathrm{~h}$, and BBR pretreatment inhibited inflammatory polarization. BBR could interact with TLR4 and disturb the signal transduction of the TLR4/MyD88/NFKB signalling pathway, and this might be the mechanism by which BBR attenuates inflammation in the early phase.

\section{Supplementary information}

Supplementary information accompanies this paper at https://doi.org/10. 1186/s12906-019-2710-6.

Additional file 1: Figure S1. Protein levels of TLR4 (A) and p-AMPK (B) and effects of BBR on combination of TLR4 and MyD88 in ColP assay (C) induced by LPS in Raw264.7 cells. Compared with N group, ${ }^{\#} P<0.05$, ${ }^{\# \# \# P} P$ 0.001; compared with LH group, ${ }^{*} P<0.05$.

\section{Abbreviations}

AMPK: Adenosine 5'-monophosphate (AMP)-activated protein kinase; BBR: Berberine; FBS: Fetal bovine serum; IL-1: Interleukin-1; IL-6: Interleukin-6; INOS2: Inducible nitric oxide synthase 2; LPS: Lipopolysaccharide; MIP1: Macrophage inflammatory protein 1; MyD88: Myeloid differentiation factor 88; NFKB: Nuclear transcription factor-KB; PBS: Phosphate buffered saline; T2DM: Type 2 diabete mellitus; TLR: Toll-like receptor; TNFR: Tumor necrosis factor receptor; TNF-a: Tumor necrosis factor a 


\section{Acknowledgements}

This article is supported by the National Natural Science Foundation of China (No.81904158, 81703869).

\section{Authors' contributions}

FL, HD, ZH and JG designed the study. JG, JL, GC, XQ, MH, FY, KF, DW, SJ, YZ and $\mathrm{WH}$ performed the experiments. $\mathrm{ZH}, \mathrm{FL}$ and $J \mathrm{G}$ wrote the manuscript. All authors approved the paper to be published.

\section{Availability of data and materials}

The datasets used and/or analysed during the current study are available from the corresponding author on reasonable request.

\section{Ethics approval and consent to participate}

The study was approved by the animal ethics committee of Huazhong University of Science and Technology (NO.2015S508).

\section{Consent for publication}

All authors agree to publish the manuscript.

\section{Competing interests}

The authors declare that they have no competing interests.

\section{Author details}

${ }^{1}$ Department of Integrated Traditional Chinese and Western Medicine, Tongji Hospital, Tongji Medical College, Huazhong University of Science and Technology, Wuhan 430030, Hubei, China. ${ }^{2}$ Institute of Integrated Traditional Chinese and Western Medicine, Tongji Hospital, Tongji Medical College, Huazhong University of Science and Technology, Wuhan 430030, Hubei, China.

Received: 13 May 2019 Accepted: 3 October 2019

Published online: 19 November 2019

\section{References}

1. Hotamisligil GS. Inflammation, metaflammation and immunometabolic disorders. Nature. 2017:542(7640):177-85. https://doi.org/10.1038/ nature21363.

2. Nagareddy PR, Kraakman M, Masters SL, Stirzaker RA, Gorman DJ, Grant RW, Dragoljevic D, Hong ES, Abdel-Latif A, Smyth SS, et al. Adipose tissue macrophages promote myelopoiesis and monocytosis in obesity. Cell Metab. 2014;19(5):821-35. https://doi.org/10.1016/j.cmet.2014.1003.1029.

3. Gregor MF, Hotamisligil GS. Inflammatory mechanisms in obesity. Annu Rev Immunol. 2011;29:415-45. https://doi.org/10.1146/annurev-immunol031210-101322.

4. Williamson RT. On the treatment of glycosuria and diabetes mellitus with sodium salicylate. Br Med J. 1901;1(2100):760-2.

5. Hotamisligil GS, Shargill NS, Spiegelman BM. Adipose expression of tumor necrosis factor-alpha: direct role in obesity-linked insulin resistance. Science. 1993;259(5091):87-91.

6. Goldfine AB, Fonseca V, Jablonski KA, Pyle L, Staten MA, Shoelson SE. The effects of salsalate on glycemic control in patients with type 2 diabetes: a randomized trial. Ann Intern Med. 2010;152(6):346-57. https://doi.org/10. 7326/0003-4819-7152-7326-201003160-201000004.

7. Goldfine AB, Fonseca V, Jablonski KA, Chen YD, Tipton L, Staten MA, Shoelson SE. Salicylate (salsalate) in patients with type 2 diabetes: a randomized trial. Ann Intern Med. 2013;159(1):1-12. https://doi.org/10.7326/ 0003-4819-7159-7321-201307020-201300003.

8. Johnson AM, Olefsky JM. The origins and drivers of insulin resistance. Cell. 2013;152(4):673-84. https://doi.org/10.1016/j.cell.2013.1001.1041.

9. Hernandez ED, Lee SJ, Kim JY, Duran A, Linares JF, Yajima T, Muller TD, Tschop MH, Smith SR, Diaz-Meco MT, et al. A macrophage NBR1-MEKK3 complex triggers JNK-mediated adipose tissue inflammation in obesity. Cell Metab. 2014;20(3):499-511. https://doi.org/10.1016/j.cmet.2014.1006.1008 Epub 2014 Jul 1017

10. Lackey DE, Olefsky JM. Regulation of metabolism by the innate immune system. Nat Rev Endocrinol. 2016;12(1):15-28. https://doi.org/10.1038/ nrendo.2015.1189 Epub 2015 Nov 1010.

11. Chen X, Zhuo S, Zhu T, Yao P, Yang M, Mei H, Li N, Ma F, Wang JM, Chen S, et al. Fpr2 Deficiency Alleviates Diet-Induced Insulin Resistance Through Reducing Body Weight Gain and Inhibiting Inflammation
Mediated by Macrophage Chemotaxis and M1 Polarization. Diabetes. 2019;12(10):db18-0469.

12. Pernes G, Lancaster Gl, Murphy AJ. Take me to the liver: adipose tissue macrophages coordinate hepatic neutrophil recruitment. Gut. 2018;67:12046. https://doi.org/10.1136/gutjnl-2017-315393.

13. Jourdan T, Godlewski G, Cinar R, Bertola A, Szanda G, Liu J, Tam J, Han T, Mukhopadhyay B, Skarulis MC, et al. Activation of the Nlrp3 inflammasome in infiltrating macrophages by endocannabinoids mediates beta cell loss in type 2 diabetes. Nat Med. 2013;19(9):1132-40. https://doi.org/10.1038/nm. 3265 Epub 2013 Aug 1118.

14. Boutens L, Hooiveld GJ, Dhingra S, Cramer RA, Netea MG, Stienstra R. Unique metabolic activation of adipose tissue macrophages in obesity promotes inflammatory responses. Diabetologia. 2018;14(10):017-4526.

15. Kawano Y, Nakae J, Watanabe N, Kikuchi T, Tateya S, Tamori Y, Kaneko M, Abe T, Onodera M, Itoh H. Colonic Pro-inflammatory Macrophages Cause Insulin Resistance in an Intestinal Ccl2/Ccr2-Dependent Manner. Cell Metab. 2016;24(2):295-310. https://doi.org/10.1016/j.cmet.2016.1007.1009.

16. Zajac E, Schweighofer B, Kupriyanova TA, Juncker-Jensen A, Minder P, Quigley JP, Deryugina El. Angiogenic capacity of M1- and M2-polarized macrophages is determined by the levels of TIMP-1 complexed with their secreted proMMP-9. Blood. 2013;122(25):4054-67. https://doi.org/10.1182/ blood-2013-4005-501494 Epub 502013 Oct 501430.

17. Moghaddam AS, Mohammadian S, Vazini H, Taghadosi M, Esmaeili SA, Mardani F, Seifi B, Mohammadi A, Afshari JT, Sahebkar A. Macrophage plasticity, polarization and function in health and disease. J Cell Physiol. 2018;10(10):26429

18. Mercalli A, Calavita I, Dugnani E, Citro A, Cantarelli E, Nano R, Melzi R, Maffi $P$, Secchi A, Sordi V, et al. Rapamycin unbalances the polarization of human macrophages to M1. Immunology. 2013;140(2):179-90. https://doi.org/10. 1111/imm.12126.

19. Shan B, Wang X, Wu Y, Xu C, Xia Z, Dai J, Shao M, Zhao F, He S, Yang L, et al. The metabolic ER stress sensor IRE1alpha suppresses alternative activation of macrophages and impairs energy expenditure in obesity. Nat Immunol. 2017; 18(5):519-29. https://doi.org/10.1038/ni.3709 Epub 2017 Mar 1027.

20. Liu Y, Liu X, Hua W, Wei Q, Fang X, Zhao Z, Ge C, Liu C, Chen C, Tao Y, et al. Berberine inhibits macrophage M1 polarization via AKT1/SOCS1/NF-kappaB signaling pathway to protect against DSS-induced colitis. Int Immunopharmacol. 2018;57:121-31. https://doi.org/10.1016/j.intimp.2018. 1001.1049 Epub 2018 Feb 1024.

21. Gong J, Hu M, Huang Z, Fang K, Wang D, Chen Q, Li J, Yang D, Zou X, Xu L, et al. Berberine attenuates intestinal mucosal barrier dysfunction in Type 2 diabetic rats. Front Pharmacol. 2017:8:42. https://doi.org/10.3389/fphar.2017. 00042 eCollection 02017.

22. van der Vorst EPC, Theodorou K, Wu Y, Hoeksema MA, Goossens P, Bursill CA, Aliyev T, Huitema LFA, Tas SW, Wolfs IMJ, et al. High-Density Lipoproteins Exert Pro-inflammatory Effects on Macrophages via Passive Cholesterol Depletion and PKC-NF-kappaB/STAT1-IRF1 Signaling. Cell Metab. 2017;25(1):197-207. https://doi.org/10.1016/j.cmet.2016.1010.1013 Epub 2016 Nov 1017.

23. Lin JS, Lai EM. Protein-protein interactions: co-Immunoprecipitation. Methods Mol Biol. 2017;1615:211-9. https://doi.org/10.1007/1978-1001-49397033-1009 1017.

24. Ramkhelawon B, Hennessy EJ, Menager M, Ray TD, Sheedy FJ, Hutchison S, Wanschel A, Oldebeken S, Geoffrion M, Spiro W, et al. Netrin-1 promotes adipose tissue macrophage retention and insulin resistance in obesity. Nat Med. 2014;20(4):377-84. https://doi.org/10.1038/nm.3467 Epub 2014 Mar 1032.

25. McNelis JC, Olefsky JM. Macrophages, immunity, and metabolic disease. Immunity. 2014;41(1):36-48. https://doi.org/10.1016/j.immuni.2014.1005.1010.

26. Xiong XQ, Geng Z, Zhou B, Zhang F, Han Y, Zhou YB, Wang JJ, Gao XY, Chen Q, Li YH, et al. FNDC5 attenuates adipose tissue inflammation and insulin resistance via AMPK-mediated macrophage polarization in obesity. Metabolism. 2018;25(18):30019-2.

27. Cameron AR, Morrison VL, Levin D, Mohan M, Forteath C, Beall C, McNeilly $A D$, Balfour DJ, Savinko T, Wong AK, et al. Anti-inflammatory effects of metformin irrespective of diabetes status. Circ Res. 2016;119(5):652-65. https://doi.org/10.1161/CIRCRESAHA.1116.308445 Epub 302016 Jul 308414.

28. Ballak DB, van Diepen JA, Moschen AR, Jansen HJ, Hijmans A, Groenhof GJ, Leenders F, Bufler P, Boekschoten MV, Muller M, et al. IL-37 protects against obesity-induced inflammation and insulin resistance. Nat Commun. 2014;5: 4711. https://doi.org/10.1038/ncomms5711.

29. Xu Y, Jagannath C, Liu XD, Sharafkhaneh A, Kolodziejska KE, Eissa NT. Tolllike receptor 4 is a sensor for autophagy associated with innate immunity. 
Immunity. 2007;27(1):135-44. https://doi.org/10.1016/j.immuni.2007.1005. 1022 Epub 2007 Jul 1019.

30. Jia L, Vianna CR, Fukuda M, Berglund ED, Liu C, Tao C, Sun K, Liu T, Harper $\mathrm{MJ}$, Lee CE, et al. Hepatocyte Toll-like receptor 4 regulates obesity-induced inflammation and insulin resistance. Nat Commun. 2014;5:3878. https://doi. org/10.1038/ncomms4878

31. Raetzsch CF, Brooks NL, Alderman JM, Moore KS, Hosick PA, Klebanov S, Akira S, Bear JE, Baldwin AS, Mackman N, et al. Lipopolysaccharide inhibition of glucose production through the Toll-like receptor-4, myeloid differentiation factor 88 , and nuclear factor kappa b pathway. Hepatology. 2009;50(2):592-600. https://doi.org/10.1002/hep.22999.

32. Sujitha S, Dinesh P, Rasool M. Berberine modulates ASK1 signaling mediated through TLR4/TRAF2 via upregulation of miR-23a. Toxicol Appl Pharmacol. 2018; 359:34-46. https:/doi.org/10.1016/j.taap.2018.1009.1017 Epub 2018 Sep 1018.

33. Li R, Chen Y, Shi M, Xu X, Zhao Y, Wu X, Zhang Y. Gegen Qinlian decoction alleviates experimental colitis via suppressing TLR4/NF-kappaB signaling and enhancing antioxidant effect. Phytomedicine. 2016;23(10):1012-20. https:// doi.org/10.1016/j.phymed.2016.1006.1010 Epub 2016 Jun 1015.

34. Sheedy FJ, Palsson-McDermott E, Hennessy EJ, Martin C, O'Leary JJ, Ruan Q, Johnson DS, Chen Y, O'Neill LA. Negative regulation of TLR4 via targeting of the proinflammatory tumor suppressor PDCD4 by the microRNA miR-21. Nat Immunol. 2010;11(2):141-7. https://doi.org/10.1038/ni.1828 Epub 2009 Nov 1029.

35. Doyle SL, Husebye H, Connolly DJ, Espevik T, O'Neill LA, McGettrick AF. The GOLD domain-containing protein TMED7 inhibits TLR4 signalling from the endosome upon LPS stimulation. Nat Commun. 2012;3:707. https://doi.org/ 10.1038/ncomms 1706

\section{Publisher's Note}

Springer Nature remains neutral with regard to jurisdictional claims in published maps and institutional affiliations.

Ready to submit your research? Choose BMC and benefit from:

- fast, convenient online submission

- thorough peer review by experienced researchers in your field

- rapid publication on acceptance

- support for research data, including large and complex data types

- gold Open Access which fosters wider collaboration and increased citations

- maximum visibility for your research: over $100 \mathrm{M}$ website views per year

At $\mathrm{BMC}$, research is always in progress.

Learn more biomedcentral.com/submissions 